concussion. There are other chapters of interest on the role of fusion in the management both of cervical and of lumbar pain.

The radiographs in this volume are rather disappointingly reproduced, and there are several occasions when the discussants (whose remarks are quoted at the end of each chapter) refer to data which are not included in the published text.

Although relatively few are likely to want to include it in their personal libraries, this is a volume which many will want to place on the shelves of their departmental library in order to refer to it from time to time.

ANTONY JEFFERSON

PARKInSONISM: Physiology, Pharmacology and Treatment By Donald B. Calne. (Pp. xii $+136 ; 21$ figures; £2.25.) Edward Arnold: London. 1970.

To make the most effective use of L-dopa in the treatment of Parkinsonism it is desirable to have some understanding of the mechanisms of the main symptoms of the syndrome. This book contains a valuable discussion of some aspects of motor control but the space devoted to the basal ganglia is surprisingly meagre and omits much relevant work. The righting reflexes are scarcely mentioned. Hypokinesia is described but its physiological basis not adequately discussed despite the amount of space devoted to motor control.

The pharmacology of L-dopa and dopaminergic transmission is adequately covered and the survey of treatment is good. As indicated in the title, the book does not deal with the different pathological types of Parkinsonism. Surgical treatment is not covered, nor the relative place of surgery and the different forms of drug treatment.

These comments outline some of the defects of the book, but only because it has the makings of a really outstanding one. It is nevertheless an excellent short account of a topical subject, well produced and reasonably priced.

J. A. SIMPSON

PROGRESS IN BRAIN RESEARCH. Volume 32: Pituitary, Adrenal, and the Brain. Edited by D. De Wied and J. A. W. M. Weijnen. (Pp. xv + 357; illustrated; price not stated.) Elsevier: Amsterdam. 1970.

This volume contains a collection of papers from over 60 eminent contributors delivered at an international conference held in the Netherlands in July 1969. There are four sections each dealing with a main theme.

The first section discusses the central nervous mechanisms for the release of ACTH, and the feed-back control of adrenal corticosteroids over the ACTH output. In one contribution it is postulated that the immature central nervous system might be programmed by adrenocortical hormones with regard to the release of ACTH in response to stress. Such an effect would be analogous to the organization of the nervous system under the influence of gonadal hormones.

The second section deals with the effects of ACTH and adrenocortical hormones on the nervous system, and includes studies of the chemosensitivity of parts of the brain to corticosteroids. Novel techniques are described, such as the use of multibarrelled micropipettes for recording from single neurones while simultaneously delivering minute doses of corticosteroids by microelectrophoresis or iontophoresis; at the end of the experiment dyes may be ejected from one of the barrels thus permitting accurate histological identification.

The third theme is concerned with the action of ACTH and corticosteroids on conditioned and motivated behaviour in animals. It is postulated that these hormones act by altering the threshold levels of central nervous processes. Most studies report that ACTH facilitates the acquisition of conditioned reflexes whereas corticosteroids have the reverse effect.

The last section consists of a number of clinical studies. Enhanced intelligence quotients are reported in patients with the congenital adrenogenital syndrome and in girls with progestin-induced hermaphroditism. There are also interesting observations on the secretion rates of cortisol in anxious subjects, in depressives showing 'psychotic disorganization', and in patients after admission to hospital.

The research reported in this book is highly specialized in the sense that it is confined to the pituitary-adrenalc axis to the exclusion of other functions of the pituitary controlled by the brain. Yet it covers a wide range from 0 studies of single neurones to observations in man. A compilation of the papers read at a conference must inevitably appear unsystematic in its presentation. Conflicting data can easily be discerned but this carries the advantage of conveying to the reader areas of $2-\overrightarrow{0}$ uncertainty in a field of research which is extending $D_{\mathbb{D}}$ rapidly. This volume will be welcomed by specialists, $\varnothing \varnothing$ including clinicians, who wish to keep abreast of this area of neuroendocrinology.

G. F. M. RUSSELL

DIE KOMBINATION HYSTERISCHER UND EPILEPTISCHER ANFÄLLE. (THE COMBINATION OF HYSTERICAL AND EPILEPTIC SEIZURES). By Franz Rabe. Neurology Series Vol. 5. (pp. 112; DM. 38.) Springer: Berlin.

This book is a valuable contribution to the existing voluminous literature on epilepsy. Its value is enhanced by the fact that Dr. Rabe redirects the reader's attention to the late 19 th and early 20 th century when a combination of epileptic and hysterical attacks was not only discussed but accepted by many. Charcot's 'hysteroepilepsie à crises distinctes' would nowadays correspond to the combination of typical hysterical and epileptic seizures in patients with so-called epileptic personality changes, while Charcot's 'hysteroepilepsie à crises combinées' can be traced to the modern terminologies of affective, reactive and 'awakening' epilepsy.

Dr. Rabe denies the identity of hysteroepilepsy with psycho-motor seizures. He accepts the fact that epileptic and hysterical seizures may occur contemporaneously or may follow each other, and the apparent faulure of the treatment of epilepsy may be due to the fact that hysterical seizures may have taken the place of true epileptic ones and have been misdiagnosed.

In many, the differential diagnosis may be difficult and 
only admission to hospital and expert clinical observation may be able to differentiate the two types. Electroencephalography during and between attacks can be of the greatest value. In support of his main thesis Dr. Rabe adduces the case history of 41 patients with combined hysterical and epileptic seizures which will surely convince the sceptic.

The author cites Kraepelin's belief that the two types of seizures may be measures taken by the organism to protect its homeostasis, but Dr. Rabe admits that the combination still escapes our understanding; he points out that in these patients there is a fundamental disturbance between the ego and the surrounding which bridges the apparently trenchant division between the two types of attacks.

\section{J. SCHORSTEIN}

ANAESTHESIA For NEUROLOGICAL SURGery By P. B. McComish and P. O. Bodley (Pp. 412; illustrated; £5.50.) Lloyd-Luke: London. 1971.

This eminently readable book presents modern practice in neuroanaesthesia in the short compass of under 400 pages. The authors are to be congratulated on producing a volume of value and interest, not only to the anaesthetist but to his colleagues in surgery and neurology. By including historical notes and pathology, in the author's words, "a background of knowledge is created so that the anaesthetist may better comprehend, and enjoy, neuroanaesthesia.' The book is divided into four sections: historical, fundamental concepts of the intracranial milieu, basic techniques in neuroanaesthesia, and methods of anaesthesia for neurosurgical procedures. The references at the end of each chapter are particularly extensive and further reading is also given. It will be of value as a textbook for reference purposes and as a manual of instruction for more than the trainee-anaesthetist as modestly suggested by the authors. With increasing trauma and the difficulty in staffing accident and emergency units, the chapter on head injuries and the associated resuscitation, as first-aid and in hospitals, can be recommended, particularly so, when junior staff may be required to deal with such demanding situations.

The illustrations and charts are clear and the book produced and printed so as to make it a pleasure to handle.

$$
\text { A. H. GRANAT }
$$

HANDBOOK OF LEPROSY By W. H. Jopling. (Pp. iv +91 ; illustrated; £1·15.) Heinemann: London. 1971.

This small paper-back book is highly recommended. Written as a short handbook for para-medical workers, it contains sufficient concise but reliable information to suit the needs of all who have occasional need to know the essentials of leprosy, such as neurologists working in a sea-port or in areas of high immigration. It does not contain sufficient data for the neuropathologist, who will be surprised at the function attributed to Schwann cells, and it makes no mention of the diagnostic value of nerve conduction studies, but for the intended readership it is excellent.

J. A. SIMPSON
NEUROPSYCHOLOGIE: Alituelle Probleme (NEUROPSYCHOLOGY: Pressing Problems) Edited by Manfred Haider. (Pp. 151; illustrated; DM. 22.) Hans Huber: Stuttgart. 1971.

Neuropsychology is a bastard word which describes an itch, but as yet we do not know where and how to scratch. Where is the seat of humour, where in the brain does a man compose a poem, what in electrical, biochemical, or histological terms makes this one unhappy the other romantic and yet another apathetic? Where and above all (as St. Paul would have it) is charity? Once found and measured it would be only a short step to regulate, to change and to bring it into conformity. There at last lies 'the rub'. Happily the day seems as far distant today as it did when Descartes firmly placed the human soul into the pineal gland.

The aim of this brief book is to introduce and to summarize the correlation of electrical events in the central nervous system with psychical happenings. The harvest is still but a poor one, although the number of harvesters grows each year, and the number of publications is growing apace.

In the booklet Creutzfeldt tries to find an explanation for the origin of spontaneous alterations in the EEG; how evoked and how the slower cerebral potentials come about. Grünewald discusses the basic neuropsychological investigations and their various problems.

Other papers deal briefly with the findings which may accompany stereotactic brain operations and the effects of stimulating various brain structures on brain-electrical phenomena as well as on experience and conduct. Clinical benefits are foreseen.

Finally methodological problems are presented and their possible future clinical importance is foreshadowed.

The six essays are well presented and well edited. Many psychologists and neurophysiologists will find them valuable.

J. SCHORSTEIN

BIOCHEMISTRY, SCHIZOPHRENIAS AND AFFECTIVE ILLNESSES Edited by Harold E. Himwich. (Pp. xiv +500 ; illustrated.) Williams and Wilkins: Baltimore. 1970.

Over the past 20 years the arrival of a host of new psychotropic drugs has stimulated both treatment and research undertaken by psychiatrists. In the sphere of therapeutics the results can already be seen in the greatly improved symptomatic management of many psychiatric illnesses. Perhaps inevitably, these largely empirical successes have re-awakened interest in the possibilities of identifying a chemical basis for mental disorders, especially the functional psychoses. Here, however, problems of method and technique have so far frustrated most of the high hopes raised by the speculations and theories of the biochemists and pharmacologists. This book brings together a number of the more promising leads in 15 chapters which range widely to cover such diverse topics as catecholamine metabolism, electrolyte disturbances, steroid metabolism, indoleamines, biological rhythms, and carbohydrate metabolism. Together they constitute a useful overview of a large and growing body of investigations, justifying the claim advanced by Seymour Kety 